\title{
Jogo de RPG no ensino e aprendizagem de narrativas não-lineares
}

\author{
Dinorá Fraga; Felipe Silveira Pedroso ${ }^{1}$
}

Os super-heróis em gibis, desenhos animados, videogames e filmes estão entre os assuntos mais discutidos por pais, educadores e psicólogos. Com base na própria experiência e em depoimentos, o jornalista, roteirista de quadrinhos (Batman, $\underline{\text { Homem- }}$ Aranha, Pokémon...) e especialista em cultura pop Gerard Jones defende no livro Brincando de matar monstros que os jogos de computador e todo conteúdo televisivo não são escolas de violência real, mas que crianças e adolescentes precisam da violência de fantasia para melhor liberar seu emocional e até combater medos e angustias na vida real. Em diversas discussões entre adultos envolvidos com o tema e usuários desses jogos, o autor conclui que ausência de games, ou qualquer outra forma de entretenimento, com temas violentos, no cotidiano de uma criança ou jovem, pode contribuir para que esta violência apareça na vida real.

O livro tem como exemplos diversos seriados e desenhos de tevê Power Ranges, Pokémon e Superman, e jogos como Doom e Quake (jogos de tiros, em primeira pessoa). Com base em suas pesquisas e depoimentos de amigos e especialistas, são mapeadas como todas essas formas de entretenimento, mesmo que violentas, podem influenciar nas características emocionais, sociais e na personalidade da criança na fase de crescimento.

Na sua infância, Jones era um garoto tímido. Sua mãe, que era professora, levou pra casa os gibis do Incrível Hulk, que, segundo ele, o libertou para o mundo, através da figura de violência do Hulk, que lhe possibilitava demonstrar tudo o que, nele, estava reprimido. Isto aconteceu, anos mais tarde, com uma garota em uma de suas viagens, como conferencista. Ela era muito solitária, como ele, na infância. Acabou por conhecer um de seus gibis e toda a violência contida na história fez com que se sentisse mais poderosa e pudesse enfrentar seus medos e receios.

$\mathrm{O}$ autor cita diversas vezes que as crianças e jovens sentem, de alguma forma, medo da realidade e procuram uma espécie de poder nos jogos que não encontram no dia a dia. Esta busca pelo poder colabora com a criação do caráter e do crescimento emocional, fazendo com que possam discernir entra a violência fictícia e a violência real. Como é citado no livro, crianças que brincam de matar monstros são menos agressivas do que as que não participam de tais brincadeiras.

Às vezes, é difícil para um pai se conformar que seu filho ou sua filha está "matando" pessoas ou monstros, mesmo que sejam virtuais. Pensam que isso irá influenciá-lo (a) a tal ponto que poderá pegar uma arma e sair atirando nas pessoas. Nesse caso, o autor sugere que os pais interajam com seus filhos, participem das brincadeiras e dos momentos em que as crianças estão "matando" inimigos fictícios.

\footnotetext{
${ }^{1}$ Professora do programa de Pós-Graduação em Lingüística Aplicada Unisinos; coordenadora da pesquisa Planificação Textual em ambiente informatizado; Bolsista de iniciação cientifica CNPQ, aluno do curso de Graduação Tecnológica em Jogos e Entretenimento Digital. 
Isso os ajudará a entendê-los e, também, abrirá espaços para conversas sobre o assunto, trazendo uma compreensão dos fatos. Para que possam desenvolver uma personalidade que lhes será útil durante toda a vida, os jovens precisam de modelos, orientação, direcionamento, comunicação e limites. Uma família sem uma boa estrutura física e psicológica acaba por ter conflitos e quem sofre são jovens e crianças, levando a um comportamento recluso e agressivo, em certos casos.

Muito se fala do conteúdo que é exposto para as crianças e jovens na televisão aberta. Muitos podem pensar que desenhos animados incitam à violência e à agressividade de quem assiste. Contudo, o autor conta fatos como o do seu filho que assistindo os Power Rangers, ficou querendo "matar" monstros para salvar seu pai. Jones tratou com a maior tranqüilidade o episódio vivido, sabendo que seu filho criou essa história para fantasiar um poder que o ajudaria a enfrentar problemas.

O livro traz referência a estudos em que é evidenciado que a grande maioria de crianças e jovens que pegam em armas cresceu em lares onde a violência e armas eram do seu cotidiano. Mas, apesar disso, os pesquisadores apontam que não é possível fazer uma correlação com o fato de uma criança gostar de armas de brinquedo e brincar, simbolicamente, de atirar com os dedos, por exemplo.

Também, alguns jovens têm demasiada raiva contida ou são mais propensos a absorver as cenas de violências e esses são casos que devem ser observados pelos pais e especialistas porque jogos ou qualquer outro entretenimento violento poderão potencializar a raiva contida nestes jovens, o que poderá causar fatalidades, como na escola em $\underline{\text { Columbine. }}$

Por fim, Gerard Jones desmistifica a afirmativa de que os jogos e toda forma de entretenimento violento tornam as crianças agressivas.

\section{Referências bibliográficas utilizadas pelo autor}

O autor oferece um vasto material bibliográfico para subsidiar suas afirmativas ao longo do livro. Utilizando o critério de atualidade: textos a partir de 1997 e presença de dados completos das referências, traremos as indicações referentes a cada capitulo do livro, possibilitando o acesso a sites dos termos indicados.

Temas:

Ser Forte

BRIAN SUTTON-SMITH. O mais recente The Ambiguity of Play (Cambridge: Harvard University Press, 1997).

Só enxergamos o que estamos preparados para enxergar.

HELEN SMITH, The Scarred Heart: Understanding and Identifying Kids Who Kill.

A varinha de condão

DANIEL S. ACUFF E ROBERT H. REITHER, What Kids Buy and Why: The Psychology of Marketing to Kids (Nova York: Free Press, 1997).

A luta Legítima 
LENORE TERR, Beyond Love and Work: Why Adults Need to Play (Nova York: Scribner, 1999).

O poder das meninas

JUSTINE CASSELL E HENRY JENKIS, editors, From Barbie to Mortal Kombat: Gender an Computer Games (Cambridge: MIT Press, 1998).

Depois da tempestade vem a calmaria

Joint Statement on the Effects of Entertainment Violence on Children, Encontro Congressional de Saúde Pública, 26 de julho de 2000.

Fantasia e realidade

MIKE A. MALES, Framing Youth: 10 Myths About the Next Generation (Monroe, Maine: Common Courage Press, 1999), págs. 280-281.

A coragem para mudar

JEFFREY GOLDSTEIN, editor, Why We Watch: The attractions of Violence Entertainment (Oxford: Oxfor University Press, 1998).

Caçadores de vampiros

SHARON R. MAZZARELLA e NORA ODOM PECORA, editoras,. Games de atirar

JONATHAN L. FREEDMAN, Media Violence and Its Effect on Aggression: Assessing the Scientific Evidence (Toronto: University of Toronto Press, 2002).

Modelo, espalhamento e orientação

LYNN PORTON, The Romance of Risk: Why Teenagers Do the Things They Do (Nova York: Dutton, 2000).

Não tão sozinhos assim

HELEN SMITH, The Scarred Heart: Understanding and Identifying Kids Who Kill. A aventura do crescimento

MICHAEL CHABON, The Amazing Adventures of Kavalier and Clay (Nova York: Random House, 2000).

\section{Mas afinal, o que é um jogo? ${ }^{2}$}

A pergunta soa estranha, praticamos tão comumente nossa inserção lúdica preferida sem questionarmos o que exatamente estamos fazendo. Johan Huizinga afirmou que até os animais brincavam. A partir disso, garante que o jogo é um fenômeno fisiológico ou um reflexo psicológico, não vinculado a qualquer civilização,

\footnotetext{
${ }^{2}$ Este texto foi elaborado por Geovane Dantas Lacerda, bolsista FAPERGS; aluno do curso de Históriae .
} 
surgindo antes da racionalidade. De qualquer forma, a intensidade do jogo não pode ser explicada apenas pela biologia, é preciso analisá-lo também como elemento cultural.

Nos primórdios da linguagem, o jogo (faz-de-conta, lúdico) já estava presente. $\mathrm{O}$ universo imaginário do culto e do mito, a arte, a poesia e tantas outras criações culturais têm sua base na essência do jogo. Algo tão amplo não poderia ser expresso em uma simplória "redução de termos". Nem a estética nem a lógica o abarcam completamente.

Huizinga, em sua obra Homo Ludens, (2001) limita seu objeto de pesquisa a partir do jogo social. Este possui algumas características-chave:

O jogo só se torna uma necessidade urgente na medida em que o prazer por ele provocado o transforma em uma necessidade urgente; Supérfluo, jamais uma tarefa, um evento para as horas de ócio;

Trata-se de uma evasão da vida "real" para uma esfera temporária de atividade com orientação própria Até mesmo uma criança sabe que está só brincando, ainda que interaja neste universo criado com a maior seriedade, sendo absorvida por esta ambientação lúdica;.

Enquanto o jogo está ocorrendo tudo é movimento, mudança, alternância, sucessão. Quando o jogo chega ao fim, o mundo criado desvanece. Mas esta limitação não alcança a memória, a estrutura interna pode ser repetida a qualquer momento;

Mundos temporários dentro de um mundo habitual, essa é a proposta. O jogo cria seu próprio ritmo e harmonia (distanciado do real), uma ordem absoluta própria. Torna-se sagrado em seu espaço físico, dentro dele respeitam-se determinadas regras. Quebrá-las é quebrar também a magia do jogo, lançar todos os participantes de volta ao "lugar comum";

Os jogadores tornam-se amigos através desta afinidade em comum. Criam uma comunidade permanente, fora do lúdico e se tornam "separadamente juntos";

Numa tentativa de resumir as características formais do jogo, poderíamos considerá-lo uma atividade livre, conscientemente tomada como não séria e exterior à vida habitual, mas ao mesmo tempo capaz de absorver o jogador de maneira intensa e total. "É uma atividade desligada de todo e qualquer interesse material, com a qual não se pode obter qualquer lucro, praticada dentro de limites temporais e espaciais próprios, segundo certa ordem e certas regras." Sendo um jogo, o $\underline{\mathrm{RPG}}$ se enquadraria facilmente nestas características.

Em uma ambientação complexa e envolvente, o lúdico dentro do jogo de RPG se manifesta de forma intensa. Quando um jogador fala "estamos na taverna...", ele não fugiu sua percepção do espaço-tempo real, mas tem a visualização de um outro espaço, o espaço de seu imaginário Nem tudo são possíveis ao personagem de RPG. Para limitar suas capacidades, existem certas regras. "Saltou" / "não saltou", "acertou" / "não acertou" são definidos através de testes. Considerando-se que não há competitividade em um jogo de RPG (aqui se distancia da visão de Huizinga, que acreditava na competição como característica básica de um jogo), burlar a regra é fugir da própria

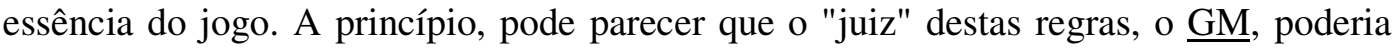
ser o "vilão" do jogo, mas essa é uma visão errônea. O Mestre de Jogo define o espaço- 
tempo da trama (tudo aquilo que não são os personagens, nestes o GM não tem controle direto), tanto os adversários quanto os aliados.

A já citada desnecessidade de um fator competitivo dentro do jogo não o torna menos emocionante. Todo o personagem possui uma busca, um objetivo. Devido à complexidade do processo de criação do personagem, estes objetivos podem ser quantitativamente e qualitativamente variados, podem ainda ser coletivos ou não.

Comparando a mecânica do RPG com o texto de Huizinga, vale lembrar um fenômeno comum entre os RPGistas, citado no livro Homo Ludens: Talvez pela própria mecânica do jogo, um grupo de RPG tende a ser unido, a formar-se como grupo social. Muito comumente os jogadores de RPG criam laços de amizade com as pessoas que compartilham de seu hobby, especialmente integrantes do mesmo grupo, como diz o autor: "As comunidades de jogadores geralmente tendem a tornarem-se permanentes, mesmo depois de acabado o jogo. (...) Mas a sensação de estar separadamente juntos, numa situação excepcional, de partilhar algo importante, afastando-se do resto do mundo e recusando as normas habituais, conserva sua magia para além da duração de cada jogo" (Huizinga, 1938). O universo ficcional acaba com o fim do jogo, mas sendo uma atividade de cooperação e em grupo, as relações entre os jogadores continuam. Grupos de RPG são, em imensa maioria, grupos de amigos.

Emoção é um conceito primordial neste divertimento. A capacidade alocutiva do jogo é limitada somente pelo sistema de regras (no que está inserido o universo do descrito pelo GM). Porém, isto não é um fato despropositado. Parte da diversão do RPG reside justamente na superação dos obstáculos, na conquista do objetivo a despeito das limitações do personagem. Assim, o jogador tem controle sobre seu personagem, mas deve interagir tanto com o ambiente (incluindo os personagens dos outros jogadores) quanto com as características de seu próprio personagem. Afinal, sua criação tem personalidade, pode ser covarde, corajoso, gentil ou cruel. Numa concepção mais complexa, o personagem pode ter qualquer uma destas características de acordo com o momento. O que não se pode esquecer durante o jogo é a personalidade do mesmo ou, principalmente, negar a interpretação com o intuito de superar um problema de forma mais fácil, o que Huizinga chama de jogador desonesto ou desmancha-prazeres. Segundo o autor, "o jogador que desrespeita ou ignora as regras é um desmancha prazeres. Este, porém difere do jogador desonesto, do batoleiro, já que o último finge jogar seriamente o jogo e apresenta reconhecer o círculo mágico" (Huizinga, 1938).

Numa perspectiva cultural de base biológica, Maturana( 2004) sobre o jogo,expõe dois tipos de culturas distintas: a patriarcal e a matriarcal. Na primeira, a apropriação, a procriação, a criação de divindades autoritárias e a guerra como modo de convivência são fatores comuns. Já na cultura matriarcal a cooperação, a sensualidade, as divindades harmônicas e a valorização do companheirismo são as características principais.

A cultura patriarcal superou a matriarcal, ainda que esta resista nas relações entre mãe e filho, por exemplo. A "sutileza" contra o "direto" faz reflexo entre dois grandes nêmesis do mundo atual: o competitivo e o cooperativo. A democracia também seria filha dessa cultura denominada matriarcal. Além de uma força contrária ao autoritarismo, viria também a busca por um viver honestamente a partir de "nos fazer responsáveis de nossa racionalidade fazendo-nos responsáveis de nossos desejos." 
O autor também acredita que as conversações seriam "redes de coordenações conduzidas consensualmente e entrelaçadas com o emocionar". Para quem já conhece o Role Playing Game, isto soaria como uma descrição rápida do jogo em si. A cultura também se torna uma rede de conversações, configurando as emoções e ações de uma forma particular.

O tema primordial do RPG sempre foi a fantasia medieval, e inegável que Tolkien tem uma grande parcela de contribuição nisto. Em sua mais famosa narrativa, $\mathrm{O}$ Senhor dos Anéis, um grupo de indivíduos formidáveis, mas não perfeitos deveriam unir forças para combater um inimigo comum. No jogo de RPG, tornou-se padrão o grupo Guerreiro/Ladrão/Mago, cada qual com suas capacidades próprias, especialistas. Poderiam lutar entre si (o jogo normalmente dá direito a isso), mas perdem força. Os personagens unem-se então com um objetivo comum, onde suas habilidades diferenciadas são utilizadas cooperativamente. Superando as dificuldades desta forma, os personagens são individualmente valorizados dentro do grupo, gerando o companheirismo.

Todos os jogos popularmente conhecidos até então possuíam como premissa a competitividade. Jogos de estratégia de guerra são um exemplo disso. Muitos jogam, um ganha. Há um objetivo pré-estabelecido pelo próprio jogo (conquiste a Oceania, derrote o exército rival) e não há muito que fazer senão iniciar uma gigantesca batalha. Simulações de combate nos remetem ao trabalho de Gerda Verden-Zoller (co-autora de Amar e Brincar), o aprender através da desconfiança (perder-se a durabilidade e a intimidade de uma relação social através da hipocrisia e da agressão) é uma representação em pequena escala do que a sociedade patriarcal espera de seus indivíduos.

É provável que o RPG, enquanto nascia de uma variação de jogos de estratégia, não sabia exatamente o quão diferenciado e amplo iria se tornar. Além disso, é possível que quem decidisse ser "contra os princípios de seu personagem lutar aquela batalha" não notou que dava um passo na direção de uma porta fechada há seis mil anos. Nos encontramos nos primórdios de uma nova geração: hipertextual e sedenta por interação.

E eis que toda uma geração ansiosa por descobrir o que aconteceria se o vilão vencesse ou se o herói resolvesse escolher um caminho diferente criou seu jogo. Role Playing-Game (jogo de interpretação de papéis), mais conhecido através de sua sigla: RPG.

O RPG é basicamente um jogo onde cada jogador tem o papel de um personagem em uma história. Além dos jogadores, existe um mestre, ou coordenador, que tem como função descrever o cenário onde os personagens agirão interpretar os personagens que aparecem na história e não são interpretados pelos jogadores (chamado de NPC, Non Player Character, Personagem Sem Jogador) e, antes do jogo começar, elaborar a base do enredo e os enigmas que os personagens deverão resolver.

Para que os personagens "adquiram vida" (afinidades, limitações e personalidade), o RPG normalmente utiliza-se de fichas de personagem. Ela define o quanto o personagem sabe como ele se parece e como ele interage com o mundo. $\mathrm{O}$ 
jogador deve resolver as situações de acordo com os objetivos, personalidade e conhecimentos do seu personagem.

Para avaliar as capacidades do personagem em alguma situação mais complexa (um salto difícil, conseguir estudar um determinado assunto dois dias seguidos sem dormir, intimidar um NPC), principalmente onde há dúvida se ele seria ou não bem sucedido, utiliza-se um sistema de jogo. Na grande maioria dos sistemas um teste é feito, utilizando um sistema aleatório (dado de 6 faces, par ou ímpar, pedra-papel-etesoura) mas concedendo maiores chances se o personagem possuir atributos que o auxiliem nesta situação (descritos na ficha de personagem).

Ao fim da história cada personagem recebe um bônus pelos conhecimentos adquiridos durante o jogo. A experiência (como é chamado no jogo) aumenta as características que o personagem utilizou durante a história.

\section{Priston Tale: Um jogo como exemplo}

Priston Tale é um jogo online, do tipo MMORPG, o que significa que milhares de pessoas podem se conectar e jogar juntas. Há diversas classes de personagens, o que equivale a uma profissão, como por exemplo, cavaleiro, mago e mecânico, que podem ser escolhidas. Essas são divididas entre duas tribos, os Morions voltados para a magia e os Tempskrons voltados para a tecnologia, onde cada classe tem habilidades distintas. Devem-se acumular pontos de experiência e realizar missões para evoluir seu personagem para ir em busca de aventuras maiores e perigosas.

Se você quiser saber mais sobre o jogo acesse o endereço www.priston.com.br e clique na opção Guia do jogo no topo da página, a partir daí será possível seguir todas as etapas necessárias para jogar.

\section{Uso do jogo no ensino aprendizagem com narrativas não-lineares}

Com base no jogo Priston Tale é possível pensar na possibilidade de transformação da aventura vivida no jogo em uma narrativa. Para tanto sugerimos as seguintes etapas:

1 - Organizar um blog, em que cada aluno (a) tem o seu. Para os alunos aprenderem a criar seu blog, há possibilidade de utilizar este site www.blogger.com;

2 - Solicitar que cada aluno (a) escreva a narrativa vivida no jogo até o momento da sua primeira "morte". É importante chamar a atenção para que não descuidem da caracterização do tempo, do espaço e das personagens envolvidas. Quanto aos personagens é importante descrever o aspecto geral como, por exemplo, aparência, modo andar, estatura, expressões faciais, tom de pele e outros traços marcantes da personalidade. Após esta caracterização criar uma situação inicial que tenha quebrado o 
equilíbrio inicial, por exemplo, de repente ser atacado por um monstro ao sair da cidade; propor uma sequiência de ações desencadeadas a partir deste fato; fazer o fechamento da narrativa.

3 - É importante não esquecer de sugerir aos alunos que utilizem os recursos de som e imagem possíveis de serem inseridas no blog. Por exemplo, capturar uma imagem do personagem do jogador durante a aventura. Isso é feito através da tecla Print Screen, que salvará a imagem na pasta c:IPristonTale Imagens do computador que está sendo usado. Um a vez salva no computador, a imagem deve ser colocada em sites de armazenamento de fotos na internet, como www.imageshack.us. O armazenamento da imagem se realiza da seguinte maneira: Ao abrir o site, clique no botão Arquivo, em seguida encontre no seu computador a pasta das imagens, localizada em C: $\backslash$ KaizenGames\PristonTale\Imagens (ou no diretório escolhido quando o jogo foi instalado); após, clicar no botão host it!; A imagem será armazenada; selecionar um link entre os apresentados; copiar o link; colar o link no texto que está sendo escrito no blog.

4 - Como a narrativa é criada a partir do jogo do aluno, está sujeita as variações do que o aluno realizou. Alguns poderão ter mais o que contar, por exemplo, seqüências que envolveram que envolveram três "mortes", enquanto outros "morreram" uma só vez. Neste caso enquanto o primeiro pode continuar escrevendo outras narrativas no blog, o outro poderá voltar para o jogo. É importante que o blog siga o ritmo da escrita e do jogo de cada aluno.

5 - Uma vez que o blog apresente um número razoável de narrativas, é possível passar para a etapa seguinte que é a criação de Hiperlinks, a fim de criar seqüências nãolineares. É possível criar links para cada texto feito, assim criando uma espécie de "caminho" com opções de onde a história poderá tomar rumo, por exemplo, a narrativa começa com o personagem estando em uma cidade e a seguir ter duas opções de caminhos diferentes, ir para a estrada ou para a floresta, e assim seguindo uma narrativa que poderá ser interligada entre si.

Com isso feito, é possível um estudo dos textos criados pelos alunos (as) da escola, com o objetivo de modificar o ensino aprendizagem atual,fazendo com que o professor vivencie a realidade que seus alunos têm na cultura não escolar.

\section{Finalmente...}

Ao jogar RPG (de mesa ou o online) muitos não percebem seus benefícios. Muitas competências são desenvolvidas e potencializadas, sejam elas intelectuais, motoras ou emocionais. Não percebemos, mas ao longo do jogo adquirimos hábitos como a leitura, escrita, hábito de pesquisar sobre diversos temas e, principalmente, a aprendizagem de trabalhar em trabalho em grupo para alcançar um objetivo em comum, muito para além da necessidade da presença física...

A prática do RPG além de entreter, atua como desenvolvedor da criatividade. Podemos fantasiar aventuras, interagir com pessoas ou seres no mundo virtual, desenvolvendo a expressão verbal, organização do pensamento, narrativas, atuação perante o grupo de jogo (no caso do jogo de papel e caneta) ou argumentativas (no caso do jogo online). 
Com o RPG criamos a aventura em nossa imaginação, criamos a fantasia de estar em um lugar como se fossemos crianças. Pensamos em lugares, pessoas e monstros, falamos e interagimos até mesmo que isso só exista em nossas mentes.

Quando jogadores de RPG, aprendemos e obedecemos regras que são usadas em jogo, mas também que nos possibilitam usa-las no mundo real. Aguçamos nosso raciocínio e nossa percepção para que, através de problemas propostos, possamos visualizar de diversas maneiras soluções e respostas.

Criatividade e fantasia são elementos voltados para a infância, mas que o RPG acaba por trazê-los à tona. Jovens que se tornarão adultos deverão manter o hábito de jogar, e para aqueles que nunca jogaram nunca é tarde para começar. Voltar a trabalhar com nosso lado criança deveria ser parte de nossas vidas adultas.

RPG é cultura e por que não dizer um movimento social que a cada dia mais e mais pessoas estão aderindo e vivenciando. Ainda existe preconceito com quem jogo, dizem que é coisa do demônio, que só os loucos jogam. Eu não sou louco e muito menos adorador do demônio, jogo por que gosto me possibilita criar e imaginar, socializar com pessoas e ate me emocionar com a aventura vivida. Quem joga torna se uma pessoa mais calma, social e que consegue se expressar melhor.

O RPG online proporciona uma experiência virtual única. É possível interagir com outros jogadores do mundo todo, participar de missões para evoluir seu personagem, criar amizades. Mas uma pergunta que alguns fazem - É possível jogar e ensinar ao mesmo tempo? A resposta é sim. Sim, pois além das vantagens citadas, o mundo de jogo pode ser usado por professores, e a partir do jogo proporcionar atividades relacionadas ao que se está estudando. Há diversas pesquisas envolvendo o uso do RPG tradicional (papel e caneta), podem ser acessados neste site $\underline{\text { www.ludusculturalis.org.br }}$, para se tirar exemplos e incorporar no jogo online.

Para isso é preciso que o professor tenha alguma experiência com RPG e principalmente com o online. Uma grande quantidade de informações pode ser encontrada neste site www.rederpg.com.br, que é um portal com enfoque no RPG, seja ele online ou não. Diversos artigos são publicados por jogadores e mestres sobre temas e usos do RPG em diversos meios, sendo a educação a mais difundida.

Um exemplo de como utilizar o que foi vivenciado no RPG online seria em uma aula de matemática. Durante o jogo os jogadores poderão adquirir itens e troca-los com seus amigos ou com outros jogadores por ouro. O professor poderia aplicar o ensino de equações matemáticas com base nos itens e no comércio que foi utilizado em jogo. Ou um professor de biologia poderia comparar a fauna e flora do virtual com o real.

Isso tudo poderá ser feito, mas a iniciativa deve partir principalmente do professor. Esse deve mostrar interesse e se propor a tentar melhorar seus modos de ensino, trocando a monotonia de um livro para um ambiente informatizado e interativo, com a possibilidade de juntar o útil ao agradável. 


\section{Referências bibliográficas:}

HUIZINGA, JOHAN. Homo Ludens: O jogo como elemento da cultura; Tradução: João Paulo Monteiro; São Paulo: Perspectiva, 2001.

JONES, Gerard. Brincando de matar monstros - Por que as crianças precisam de fantasia, videogames e violência de faz-de-conta. São Paulo: Conrad Editora, 2004. 320 p.

MATURANA, Humberto R.; VERDEN-ZÖLLER, Gerda. Amar e brincar: fundamentos esquecidos do humano do patriarcado à democracia. São Paulo: Palas Athenas, 2004. $272 \mathrm{p}$ 